\title{
Consumo energético-protéico e estado nutricional de crianças menores de cinco anos, no estado de Pernambuco, Brasil
}

\author{
Energy and protein intake and nutritional status of children \\ under five years of age in Pernambuco state, Brazil
}

Risia Cristina Egito de MENEZES ${ }^{1}$

Mônica Maria OSÓRIO'

R E S U M O

\section{Objetivo}

Avaliar o consumo de energia e proteínas e associá-lo ao estado nutricional de crianças menores de 5 anos.

\section{Métodos}

Estudo transversal com 948 crianças menores de cinco anos, no Estado de Pernambuco. O consumo alimentar foi registrado utilizando o método recordatório de 24 horas. Para análise de energia e proteína foram utilizadas as Dietary Reference Intakes como referência, verificando-se o consumo mediano e a prevalência de inadequação. O estado nutricional foi avaliado utilizando a referência do National Center for Health Statistics (índices peso/idade, peso/estatura e estatura/idade). O estado nutricional das crianças com consumo abaixo e maior ou igual à referência de energia e proteína foi comparado, utilizando-se o teste " $t$ " de Student.

\section{Resultados}

O consumo mediano de energia e proteína esteve acima das ingestões dietéticas de referência, na maioria das faixas etárias. No entanto, foram encontradas prevalências de inadequação do consumo de energia $(42,4 \%)$ e de proteína (5,0\%). O percentual de desnutrição (escore- $Z<-2$ desvios-padrão) foi de 7,3\%, 1,5\% e 16,1\% para os índices peso/idade, peso/estatura e estatura/idade, respectivamente. O estado nutricional foi melhor no grupo de crianças cujo consumo de energia e proteína foi maior ou igual à referência, na maioria das faixas etárias.

\section{Conclusão}

Os dados mostraram uma acentuada restrição da ingestão de energia e, em menor proporção, de proteínas, a qual está associada ao déficit antropométrico das crianças. Portanto, há necessidade de monitoramento da ingestão alimentar dessas crianças, a fim de evitar a inadequação alimentar e nutricional e suas conseqüências prejudiciais à saúde.

Termos de indexação: consumo de alimentos; criança; estado nutricional.

\footnotetext{
1 Universidade Federal de Pernambuco, Centro de Ciências da Saúde, Programa de Pós-Graduação em Nutrição. Av. Moraes Rego, s/n., Campus Universitário, Cidade Universitária, 50670-901, Recife, PE, Brasil. Correspondência para/Correspondence to: M.M. OSÓRIO.E-mail:<mosorio@ufpe.br>.
} 


\section{A B S T R A C T}

\section{Objective}

This study aims to evaluate energy and protein intake and associate it with the nutritional status of children under five years of age.

\section{Methods}

This is a cross-sectional study with 948 children under five years of age, in the State of Pernambuco. Dietary intake was recorded using 24-hour recalls. Dietary Reference Intakes were used as reference to analyze energy and protein intake values by verifying the median intake and the prevalence of inadequacy. Nutritional status was assessed using the National Center for Health Statistics as reference (weight-for-age, weight-for-length and length-for-age indices). The Student's t-test was used to compare the nutritional status of children with intake values below, above or equal to the energy and protein reference standards.

\section{Results}

The median energy and protein intake exceeded the dietary reference intakes in most age groups. However, a prevalence of inadequacy of $42.4 \%$ for energy and $5.0 \%$ for protein were found. The percentages of malnutrition (score- $Z<-2$ standard deviation) were $7.3 \%, 1.5 \%$ and $16.1 \%$ for the weight-for-age, weight-for-length and length-for-age indices, respectively. Nutritional status was better in the group of children whose energy and protein intake were greater than or equal to the reference standard in most age groups.

\section{Conclusion}

The results showed a significant restriction of energy and protein intake, the latter in a smaller proportion, which are associated with the low anthropometric indices of the children. Therefore, it is necessary to monitor the food intake of these children in order to avoid food and nutritional inadequacy and their harmful health consequences.

Indexing terms: food consumption; child; nutritional status.

\section{N T R O D U Ç Ã O}

As condições de saúde e nutrição de uma população constituem um reflexo de seu consumo alimentar, principalmente para as crianças, cuja alimentação adequada é condição fundamental para o pleno crescimento e desenvolvimento. $\mathrm{O}$ estado nutricional, representado pelo equilíbrio entre o consumo alimentar e as necessidades metabólicas diárias específicas do organismo, indica em que proporção as necessidades fisiológicas de nutrientes estão sendo supridas ${ }^{1}$. Uma deficiência quantitativa e/ou qualitativa do consumo de nutrientes e as infecções de repetição constituem uma das causas imediatas mais significativas dos problemas de saúde e nutrição².

Conhecer o padrão de consumo alimentar de uma população torna-se essencial para o planejamento de políticas públicas de prevenção e controle das carências nutricionais. Apesar da importância dos estudos de consumo alimentar na identificação dos principais problemas nutricionais, existem grandes lacunas de informações relacionadas às questões de alimentação, devido à escassez dos mesmos ${ }^{3}$.

O inquérito dietético consiste na aplicação de um procedimento metodológico para obtenção de informações sobre consumo e hábitos alimentares individual ou coletivo, representando um instrumento capaz de identificar as inadequações alimentares ${ }^{4}$. No entanto, a avaliação dietética não deve ser usada isoladamente no diagnóstico do estado nutricional de grupos populacionais, por não descrever o mesmo, e, sim, explicar a alimentação como determinante da situação nutricional da população. Quando são detectadas inadequações nutricionais faz-se necessário realizar avaliações antropométricas, bioquímicas e clínicas para complementar o diagnóstico ${ }^{5,6}$.

Frente à importância de estimar o consumo de energia e nutrientes na identificação de problemas de saúde pública, especificamente da desnutrição energético-protéica, e para subsidiar 
o planejamento de intervenções voltadas à melhoria dessas condições, este trabalho teve por objetivo avaliar o consumo de energia e proteína em associação com o estado nutricional de crianças menores de 5 anos, no Estado de Pernambuco.

\section{MÉ TOD OS}

O estudo utilizou o banco de dados da II Pesquisa Estadual de Saúde e Nutrição (II PESN) ${ }^{7}$. O desenho foi do tipo transversal, tendo como finalidade delinear, ampliar e atualizar a situação de saúde, nutrição, alimentação e condições sociais e econômicas, com destaque para o grupo materno-infantil, sendo realizado no período de fevereiro a maio de 1997. A II PESN teve como unidade amostral as crianças menores de cinco anos. A amostra aleatória foi sorteada em três estágios: municípios, setores censitários e domicílios. Para permitir comparação dos resultados com a I Pesquisa Estadual de Saúde e Nutrição foram considerados, na seleção da amostra, os mesmos 18 municípios desta, sorteados de forma aleatória simples. Tal como nesta pesquisa, definiu-se previamente que seria investigado, em cada setor censitário, um total de 46 crianças. A partir dessa definição, foi feito um sorteio aleatório simples dos setores censitários, considerando a proporcionalidade da população de cada município, resultando 45 setores censitários. Por último, a partir do mapa censitário, foi selecionada, aleatoriamente, uma quadra e depois uma esquina dessa quadra, a partir da qual os domicílios foram visitados um a um, seguindo o sentido horário, identificando todas as crianças menores de 5 anos.

Do total de 2.078 crianças, aproximadamente, um terço foi selecionado sistematicamente para a realização do inquérito de consumo alimentar, totalizando 992 crianças menores de cinco anos, assegurando representatividade para este propósito. Dessa amostra, foram excluídas 20 crianças que se encontravam em aleitamento materno exclusivo e 24 que apresentavam informações incompletas, trabalhando-se, então, com os dados de 948 crianças.
O método recordatório de 24 horas foi utilizado para obtenção dos dados referentes ao consumo alimentar das crianças menores de 5 anos. Foi realizada entrevista domiciliar com a mãe biológica ou adotiva, ou com o indivíduo adulto responsável pelo cuidado da criança, utilizando um formulário em que eram anotados o horário das refeições, os alimentos consumidos, formas de preparo e marcas comerciais (alimentos industrializados), as quantidades preparadas, oferecidas e consumidas pela criança, em medidas caseiras e medidas de volume. Foram considerados os alimentos consumidos nas diversas refeições diárias (desjejum, lanches, almoço, jantar e ceia) e as quantidades referidas em medidas caseiras foram, posteriormente, convertidas em peso líquido.

Com as informações referentes ao consumo alimentar foi construído o banco de dados, utilizando-se o software Virtual-Nutri ${ }^{9}$ para análise da composição nutricional dos alimentos em macronutrientes, sendo inseridos aqueles não encontrados nesse programa, a partir de tabelas de composição química de alimentos ${ }^{10,11}$.

Para análise da adequação das dietas, foram adotadas, como parâmetro, as recomendações da National Academy of Sciences (NAS), do Institute of Medicine (IOM), denominadas Ingestões Dietéticas de Referência (Dietary Reference Intakes - DRI), sendo utilizado o valor da Necessidade Energética Estimada (Estimated Energy Requirement - EER) para avaliação do consumo de energia, a Necessidade Média Estimada (Estimated Average Requirement - EAR) e a Ingestão Adequada (Adequate Intake -AI) para o consumo de proteínas, para crianças maiores e menores de 6 meses, respectivamente ${ }^{12,13}$.

Para o cálculo das EER, foram utilizadas as equações para predição de gasto energético total nos diferentes estágios de vida, considerando idade, sexo, peso, estatura e atividade física. Os valores de 1,13, para o sexo masculino, e 1,16, para o feminino, foram adotados como coeficientes de atividade física de nível leve ${ }^{13}$. 
Foi calculado o consumo mediano de ingestão de energia e proteína, e não o consumo médio, considerando a grande variabilidade do desvio-padrão encontrada em estudos de ingestão dietética, em que o consumo de nutrientes, dificilmente, apresenta distribuição simétrica.

A prevalência de inadequação para energia e proteína foi calculada pela proporção de crianças do grupo que não alcançaram os valores de referência estabelecidos para o nutriente correspondente à sua necessidade. Para as crianças menores de seis meses, cuja EAR para proteína não está estabelecida, não foi possível estimar o percentual com o consumo alimentar abaixo desse valor. Foi utilizada como referência a Al, comparando-se a mediana de ingestão encontrada no grupo com esse valor, verificando-se se a mediana de ingestão excedia ou não a $\mathrm{Al}^{12,13}$.

A idade da criança foi calculada a partir da data de seu nascimento, informada pela mãe ou responsável ou obtida por meio do Registro de Nascimento ou do Cartão da Criança. A amostra foi dividida em 4 categorias (0-6 meses, 7-11 meses, 12-47 meses e 48-60 meses), para análise do consumo de proteínas e energia ${ }^{12,13}$.

Para a avaliação do estado nutricional, foram aferidas as medidas de peso e estatura, de acordo com os seguintes procedimentos: para o peso, foi utilizada balança tipo Itac, com capacidade de $25 \mathrm{~kg}$ e sensibilidade de $100 \mathrm{~g}$. As crianças foram pesadas descalças e com vestimenta mínima; para aferição da estatura foi utilizado o antropômetro de barra de madeira, com amplitude de $100 \mathrm{~cm}$ e subdivisões de $0,1 \mathrm{~cm}$. Todas as crianças foram medidas descalças. As crianças com idade até dois anos foram medidas em decúbito dorsal e aquelas entre dois e cinco anos, em posição ereta. Foram obtidas duas medidas de peso e estatura, e suas médias utilizadas para a análise.

O estado nutricional das crianças foi classificado pelos índices peso/idade (P/I), peso/estatura (P/E) e estatura/idade (E/l), expressos em valores de escore-Z. A referência antropométrica utilizada para comparação das medidas de peso e estatura foi a do National Center for Health Statistics (NCHS), de uso recomendado pela Organização Mundial de Saúde ${ }^{14}$. Essa classificação define, como ponto de corte, níveis que permitem situar a criança em uma faixa de normalidade, de acordo com a referência utilizada. Sendo considerado o escore-Z $<-2$ desvios-padrão (DP), entre $\geq-2$ e $<-1$, e $\geq-1$ DP, respectivamente, para a desnutrição, risco nutricional e eutrofia. A avaliação do estado nutricional foi realizada com o auxílio do EpiNut, do programa Epi Info, versão 6.04 (Epi Info 6.04, WHO/CDC, Atlanta, GE, USA).

Para as análises estatísticas, foi utilizado o software SPSS, versão 7.5 (SPSS Inc, Chicago, IL, USA). Inicialmente, foi verificado o comportamento das variáveis e foram observadas suas freqüências e distribuição, mediante a aplicação do teste de Kolmogorov-Smirnov. Para as variáveis contínuas, foram verificadas as medidas de tendência central (média e mediana). O teste " $t$ " de Student, para dados não pareados, foi utilizado para comparar as médias em escore-Z para os índices antropométricos (P/I, P/E e E/I) dos grupos de crianças cujo consumo de energia e proteína estava abaixo e maior ou igual aos valores das ingestões dietéticas de referência, considerando-se o valor $p<0,05$.

A II PESN atendeu às Normas Regulamentares de Pesquisas envolvendo Seres Humanos - Resolução 196/96, do Conselho Nacional de Saúde, e foi aprovada pelo Comitê de Ética em Pesquisa do Centro de Ciências da Saúde da Universidade Federal de Pernambuco.

\section{RES U L T A D O S}

A amostra estudada consistiu de crianças de 0-60 meses de idade, sendo 31,7\% residentes na Região Metropolitana do Recife, 31,3\%, no Interior Urbano e 31,0\%, no Interior Rural do Estado de Pernambuco, sendo 50,2\% delas do sexo masculino e 49,8\%, do feminino. Em relação à renda familiar, $46,1 \%$ das suas famílias percebiam uma renda mensal menor que dois salários mínimos? 
A Tabela 1 apresenta os valores de mediana de energia ingerida pelas crianças menores de cinco anos, e os percentuais daquelas com consumo abaixo da média de EER por faixa etária. No que se refere aos valores medianos de ingestão energética, verifica-se um aumento do consumo de acordo com a idade, superior à EER, em todas as faixas etárias, exceto na de 48-60 meses de idade.

A inadequação energética apresentou altas prevalências, principalmente, nas faixas etárias de 48-60 meses e 0-6 meses, em que, respectivamente, $55,2 \%$ e $49,0 \%$ das crianças apresentaram o consumo abaixo da EER. O percentual total de crianças com consumo energético inferior à EER foi de 42,4\% (Tabela1).

A Tabela 2 mostra a ingestão de proteínas, quando comparada às EAR, verificando-se, em cada grupo, o percentual das crianças com o consumo abaixo da EAR definida para as suas respectivas faixas etárias. No que se refere às medianas de ingestão, observa-se um aumento de acordo com a idade, sendo os valores de consumo de proteína superiores à EAR proposta, em todas as faixas etárias. A maior prevalência de consumo inferior à EAR foi das crianças de 48-60 meses (6,9\%). A prevalência de inadequação de proteínas para o total das crianças, entre 7-60 meses, foi de $5,0 \%$.

Apesar de 30,3\% das crianças menores de 6 meses apresentarem ingestão de proteínas abaixo do valor da ingestão adequada (AI), não é possível estimar a prevalência de inadequação para esse grupo etário. No entanto, a mediana $(16,2 \mathrm{~g})$ de ingestão de proteínas deste grupo excede a $\mathrm{Al}$ $(9,1 \mathrm{~g})$. Portanto, espera-se que a prevalência de inadequação neste grupo seja baixa.

A Tabela 3 apresenta a distribuição das crianças menores de cinco anos de acordo com o estado nutricional, classificado segundo os índices peso/idade, estatura/idade e peso/estatura. A prevalência de desnutrição (escore-Z <-2 DP), segundo esses índices, foi de 7,3\%, 1,5\% e $16,1 \%$, respectivamente. Com relação à faixa

Tabela 1. Necessidade média estimada de energia (EER), consumo mediano e prevalência de inadequação de energia por faixa etária, em crianças menores de 5 anos. Pernambuco, 1997.

\begin{tabular}{|c|c|c|c|c|c|c|}
\hline \multirow{3}{*}{ Idade (meses) } & \multirow{3}{*}{$\mathrm{n}$} & \multicolumn{4}{|c|}{$\mathrm{kcal} / \mathrm{dia}$} & \multirow{3}{*}{$\begin{array}{c}\text { Prevalência de } \\
\text { inadequação (\%) }\end{array}$} \\
\hline & & \multirow{2}{*}{$\begin{array}{l}\text { Necessidade média } \\
\text { estimada de energia }\end{array}$} & \multicolumn{3}{|c|}{ Consumo de energia } & \\
\hline & & & Valor mínimo & Mediana & Valor máximo & \\
\hline $0-6$ & 145 & 612 & 117,5 & 626,2 & $2.767,2$ & 49,0 \\
\hline $7-11$ & 117 & 721 & 311,2 & 969,2 & $2.571,4$ & 26,5 \\
\hline $12-47$ & 570 & 1051 & 112,3 & $1.156,8$ & $3.303,1$ & 41,4 \\
\hline $48-60$ & 116 & 1365 & 342,6 & $1.274,8$ & $2.781,7$ & 55,2 \\
\hline Total & 948 & - & & & & 42,4 \\
\hline
\end{tabular}

Tabela 2. Ingestões dietéticas de referência (DRI), consumo mediano e prevalência de inadequação de consumo de proteína, por faixa etária, em crianças menores de 5 anos. Pernambuco, 1997.

\begin{tabular}{|c|c|c|c|c|c|c|}
\hline \multirow{2}{*}{ Idade (meses) } & \multicolumn{2}{|c|}{ DRI (g/dia) } & \multicolumn{3}{|c|}{ Consumo de energia } & \multirow{2}{*}{$\begin{array}{c}\text { Prevalência de } \\
\text { inadequação (\%) }\end{array}$} \\
\hline & EAR & $\mathrm{Al}$ & Valor mínimo & Mediana & Valor máximo & \\
\hline $0-6(145)$ & - & 9,1 & 3,4 & 16,2 & 70,5 & - \\
\hline 7-11 (117) & 10,0 & - & 5,0 & 30,2 & 92,0 & 6,0 \\
\hline $12-47(570)$ & 11,0 & - & 1,7 & 37,2 & 166,8 & 4,4 \\
\hline $48-60(116)$ & 15,0 & - & 8,5 & 43,3 & 121,2 & 6,9 \\
\hline Total $(n=948)$ & - & - & - & - & - & 5,0 \\
\hline
\end{tabular}

EAR: necessidade média estimada; Al: ingestão adequada. 
etária de 0-6 meses, apenas 0,7\% das crianças apresentou desnutrição pelo índice peso/idade, não acontecendo o mesmo com o índice estatura/ idade, em que a prevalência de desnutrição foi de $11,0 \%$ para a mesma faixa etária. No entanto, não foram encontradas crianças desnutridas abaixo de um ano, de acordo com o índice peso/estatura.

Em relação ao risco nutricional, as prevalências se apresentaram em percentuais superiores à desnutrição moderada e grave, em todos os índices e faixas etárias. Para o total da amostra, as prevalências de risco nutricional encontradas para os índices peso/idade, peso/estatura e estatura/idade foram de $16,4 \%, 7,5 \%$ e $23,5 \%$, respectivamente.

Na Tabela 4 estão comparadas as médias do escore-Z, de acordo com os índices peso/idade, peso/estatura e estatura/idade e o consumo de

Tabela 3. Estado nutricional pelos índices peso/idade, peso/estatura e estatura/idade e por faixa etária, em crianças menores de cinco anos. Pernambuco, 1997

\begin{tabular}{lccccc}
\hline \multirow{2}{*}{ Índices } & \multirow{2}{*}{ Idade (meses) } & $\mathrm{n}$ & \multicolumn{3}{c}{ Estado nutricional (média de escore-Z) (\%) } \\
\cline { 3 - 5 } & & & $<-2$ & -2 a $<-1$ & $\geq-1$ \\
\hline Peso/idade & $0-6$ & 145 & 0,7 & 5,5 & 93,8 \\
& $7-11$ & 117 & 9,4 & 19,7 & 70,9 \\
& $12-47$ & 570 & 8,6 & 17,4 & 74,0 \\
& $48-60$ & 116 & 6,9 & 21,6 & 71,5 \\
\hline Peso/estatura & Total & 948 & 7,3 & 16,4 & 76,4 \\
& $0-6$ & 145 & 0,0 & 1,4 & 98,6 \\
& $7-11$ & 117 & 0,0 & 6,0 & 94,0 \\
& $12-47$ & 570 & 1,8 & 9,3 & 88,9 \\
\hline Estatura/idade & 116 & 3,4 & 7,8 & 88,8 \\
& $48-60$ & 948 & 1,5 & 7,5 & 91,0 \\
\hline & Total & 145 & 11,0 & 24,8 & 64,2 \\
& $0-6$ & 117 & 25,6 & 20,5 & 53,9 \\
& $7-11$ & 570 & 15,4 & 23,0 & 61,6 \\
& $12-47$ & 116 & 16,4 & 27,6 & 56,0 \\
\hline
\end{tabular}

Tabela 4. Estado nutricional pelos índices peso/idade, peso/estatura e estatura/idade e por faixa etária, em crianças menores de cinco anos, segundo a adequação de energia $(n=948)$. Pernambuco, 1997.

\begin{tabular}{lcccccc}
\hline \multirow{2}{*}{ Índice } & Idade (meses) & \multicolumn{5}{c}{ Estado nutricional (média de escore-Z) } \\
\cline { 3 - 6 } & & <EER & DP & ZEER & DP \\
\hline Peso/idade & $0-6(n=145)$ & 0,61 & 1,19 & 0,82 & 1,45 & 0,34 \\
& $7-11(n=117)$ & 0,07 & 1,95 & $-0,03$ & 1,51 & 0,77 \\
& $12-47(n=570)$ & $-0,44$ & 1,35 & $-0,04$ & 1,44 & 0,00 \\
& $48-60(n=116)$ & $-0,51$ & 1,07 & $-0,12$ & 1,61 & 0,12 \\
\hline Peso/estatura & $0-6(n=145)$ & 1,27 & 1,40 & 1,46 & 1,50 & 0,44 \\
& $7-11(n=117)$ & 1,06 & 1,97 & 0,89 & 1,62 & 0,64 \\
& $12-47(n=570)$ & 0,20 & 1,25 & 0,64 & 1,93 & 0,00 \\
& $48-60(n=116)$ & 0,10 & 1,06 & 0,85 & 2,30 & 0,02 \\
\hline Estatura/idade & $0-6(n=145)$ & $-0,62$ & 1,75 & $-0,40$ & 1,62 & 0,43 \\
& $7-11(n=117)$ & $-0,57$ & 2,48 & $-0,87$ & 1,97 & 0,50 \\
& $12-47(n=570)$ & $-0,89$ & 1,50 & $-0,68$ & 1,88 & 0,14 \\
& $48-60(n=116)$ & $-0,89$ & 1,17 & $-0,86$ & 2,16 & 0,91 \\
\hline
\end{tabular}

EER: necessidade energética média estimada; DP: desvio-padrão; *Teste " $t$ " de Student para dados não pareados. 
Tabela 5. Estado nutricional pelos índices peso/idade, peso/estatura e estatura/idade e por faixa etária, em crianças menores de cinco anos, segundo a adequação de proteína. Pernambuco, 1997.

\begin{tabular}{|c|c|c|c|c|c|c|}
\hline \multirow{2}{*}{ Índice } & \multirow{2}{*}{ Idade } & \multicolumn{4}{|c|}{ Estado nutricional (média de escore-Z) } & \multirow{2}{*}{$p^{*}$} \\
\hline & & $<$ EAR & $\mathrm{Al}^{\mathrm{a}}$ & $\geq E A R$ & $A l^{a}$ & \\
\hline \multirow[t]{4}{*}{ Peso/idade } & $0-6^{a} \quad(n=145)$ & 0,54 & 1,17 & 0,80 & 1,39 & 0,29 \\
\hline & $7-11(n=117)$ & $-1,19$ & 1,41 & 0,08 & 1,62 & 0,04 \\
\hline & $12-47(n=570)$ & $-1,05$ & 1,25 & $-0,17$ & 1,41 & 0,00 \\
\hline & $48-60(n=116)$ & $-1,53$ & 0,54 & $-0,25$ & 1,35 & 0,01 \\
\hline \multirow[t]{4}{*}{ Peso/estatura } & $0-6^{a}(n=145)$ & 0,96 & 0,88 & 1,54 & 1,61 & 0,03 \\
\hline & $7-11(n=117)$ & 0,87 & 1,18 & 0,94 & 1,75 & 0,93 \\
\hline & $12-47(n=570)$ & $-0,13$ & 1,08 & 0,48 & 1,71 & 0,08 \\
\hline & $48-60(n=116)$ & $-0,31$ & 0,88 & 0,49 & 1,81 & 0,22 \\
\hline \multirow[t]{4}{*}{ Estatura/idade } & $0-6^{a}(n=145)$ & $-0,40$ & 1,32 & $-0,56$ & 1,83 & 0,60 \\
\hline & $7-11(n=117)$ & $-2,43$ & 1,52 & $-0,69$ & 2,11 & 0,03 \\
\hline & $12-47(n=570)$ & $-1,50$ & 1,32 & $-0,73$ & 1,75 & 0,03 \\
\hline & $48-60(n=116)$ & $-2,14$ & 0,64 & $-0,78$ & 1,70 & 0,03 \\
\hline
\end{tabular}

EAR: necessidade energética média estimada; DP: desvio-padrão; aAl: ingestão adeguada; *Teste " $t$ " de Student para dados não pareados.

energia das crianças. As médias do escore-Z, exceto para as crianças de 7-11 meses, foram superiores nos grupos cujo consumo foi maior ou igual à EER, sendo essa diferença estatisticamente significante para as crianças de 12-47 meses, em relação ao índice peso/idade, e para as maiores de um ano, em relação ao índice peso/estatura.

Na Tabela 5 estão comparadas as médias do escore-Z de acordo com os índices peso/idade, peso/estatura e estatura/idade e o consumo de proteínas das crianças menores de cinco anos. Observa-se uma tendência de as médias do escore-Z serem maiores nos grupos de crianças cujo consumo protéico foi maior ou igual aos valores das EAR, exceto para o índice estatura/idade, nas crianças menores de 6 meses. Foi observada diferença estatisticamente significante nas crianças menores de 6 meses, para o índice peso/estatura, e nas maiores de 7 meses, para os demais índices.

\section{I S C U S S Ã O}

Ainda são poucos os estudos de consumo alimentar representativos de populações. A II Pesquisa Estadual de Saúde e Nutrição constitui-se um marco na realização de inquérito dietético com representatividade das crianças menores de
5 anos de idade para um estado brasileiro, vindo a preencher uma lacuna existente nos estudos de consumo alimentar. Ela permitiu a construção de um banco de dados de consumo alimentar das crianças menores de 5 anos, no Estado de Pernambuco, o qual tem dado origem a uma série de estudos sobre o consumo alimentar, tanto de ordem quantitativa como qualitativa ${ }^{15,16}$.

Avaliar o consumo alimentar não constitui uma tarefa simples, uma vez que exige o emprego de metodologias bastante detalhadas e dispendiosas, bem como entrevistadores devidamente capacitados para a coleta dos dados 4,12,17. Esses fatos não permitiram a aplicação de inquérito recordatório de 24 horas durante a realização da III Pesquisa Estadual de Saúde em Nutrição (em fase de conclusão de trabalho de campo). Nesse sentido, por enquanto, não haverá possibilidade de avaliar de forma temporal a situação de alimentação das crianças de Pernambuco e sua relação com o estado nutricional.

Por outro lado, uma vez que existe a real necessidade de interpretar os dados de consumo de acordo com as novas referências, este estudo trabalha o banco de dados de consumo, fazendo a análise de energia e de proteína baseada nas $\mathrm{DRI}^{12,13}$. Dessa maneira, abre-se perspectivas para outros estudos nessa população, com o mesmo 
modelo de análise e que sejam capazes de acompanhar a situação alimentar e nutricional das crianças.

É importante lembrar que as DRI, utilizadas neste estudo, foram estabelecidas para a população americana e canadense, portanto, sua utilização na população brasileira deve levar em consideração possíveis diferenças nos padrões alimentares dessas populações. Contudo, a utilização das DRI constitui um avanço importante no conhecimento da nutrição, representando uma revisão dos conceitos das recomendações nutricionais e de sua interpretação. As DRI são valores de referência mais completos que visam à prevenção de deficiências nutricionais, bem como do risco de doenças crônicas não transmissíveis, além de fornecer limites para a ingestão de nutrientes, de forma a prevenir os riscos de efeitos adversos de toxicidade ${ }^{12}$. Dessa maneira, permitem análises mais adequadas, assegurando um melhor diagnóstico para a formulação das políticas de saúde e nutrição. Sendo assim, a comparação dos resultados deste estudo com os relatados a seguir apresenta alguns problemas de ordem metodológica, pelo fato de se tratar de pesquisas com metodologias distintas em relação à referência das recomendações nutricionais.

A análise dos resultados obtidos neste estudo permite constatar que o consumo alimentar das crianças pernambucanas apresenta uma acentuada restrição na ingestão de energia e, em menor proporção, de proteínas.

A inadequação de energia foi evidenciada, pela primeira vez, no Brasil, no Estudo Nacional da Despesa Familiar (ENDEF, 1974/75), no qual foram encontrados coeficientes médios de adequação energética impróprios para as três áreas estudadas (Nordeste e os estados de São Paulo e Rio de Janeiro). Em relação às proteínas, os dados do ENDEF (1974/75) diferem dos encontrados neste estudo. Havia disponibilidade suficiente de proteínas em todas as regiões pesquisadas $^{6}$. As mudanças no padrão alimentar observadas nos últimos anos, visualizadas nos estudos realizados no País, também apresentam uma tendência geral elevada de consumo protéico da população urbana, sendo o consumo de energia considerado o problema nutricional de maior magnitude ${ }^{18}$. Mesmo que esses resultados representem a população de maneira geral, poder-se-ia esperar que a população infantil seguisse o mesmo padrão de consumo alimentar da família.

Avaliando o consumo alimentar de crianças menores de 5 anos, na cidade de Salvador, Assis \& Barreto $^{19}$ constataram inadequação energética e protéica, sendo a primeira superior, em todas as faixas etárias. Entretanto, a maioria dos estudos evidencia inadequação energética e não protéica, esta última ultrapassando as recomendações, em todas as faixas etárias estudadas ${ }^{20-22}$. Szarfarc et al. ${ }^{22}$, analisando a adequação alimentar das dietas de crianças menores de 5 anos, no município de São Paulo, encontraram percentuais de adequação protéica que variaram de $234,6 \%$ a $304,0 \%$. Vale ressaltar que, em nenhum desses estudos, foi calculada a prevalência de inadequação, tendo as DRI como referência ${ }^{13}$.

A partir do uso das DRI para determinar a prevalência de inadequação, Medeiros et al. ${ }^{23}$ compararam 26 crianças com dieta isenta de leite de vaca e 30 sem restrição alimentar, e Castro et al. ${ }^{24}$ estudaram 89 crianças de 24-72 meses, assistidas em creches municipais de Viçosa. Os dois estudos constataram relevante inadequação energética, mas não foram encontradas evidências de inadequação protéica.

Uma exploração mais detalhada sobre as diferenças de risco de inadequação da dieta entre as faixas etárias evidencia que os resultados deste estudo parecem concordantes com o realizado no município de São Paulo, que relacionou as condições de saúde das crianças menores de cinco anos e o consumo alimentar, apresentando, também, o consumo energético mais inadequado na faixa etária de 48-60 meses ${ }^{22}$.

Para a faixa etária de menores de 6 meses, considerando que as crianças em aleitamento materno exclusivo foram excluídas deste estudo, verifica-se que, praticamente, $50 \%$ das crianças estudadas encontram-se em risco de desenvolver 
deficiência energética. Ao mesmo tempo em que estão privadas do direito de receber leite materno de forma exclusiva, essas crianças se encontram expostas a uma alimentação qualitativa e quantitativamente deficiente ${ }^{25}$. As altas prevalências de inadequação energética e o percentual de risco nutricional para o índice estatura/idade (24,8\%) reforçam o fato de que o desmame precoce está relacionado ao risco de desnutrição das crianças nos primeiros seis meses de vida.

Estudos realizados anteriormente ${ }^{15,16}$, utilizando o mesmo banco de dados, verificaram que o leite de vaca constitui o alimento mais consumido na dieta das crianças, possivelmente o motivo da prevalência de inadequação protéica não ser tão elevada quanto a energética. Os altos percentuais de risco de inadequação energética encontrados neste estudo podem indicar um consumo quantitativamente insuficiente de alimentos ${ }^{15}$. Outros autores também demonstram a aparente contradição entre as altas freqüências do consumo de alimentos energéticos e as elevadas prevalências de inadequação energética ${ }^{21,24}$.

Apesar de o consumo mediano de energia e, em maior proporção, o de proteína, terem sido superiores às EER, EAR e Al, em, praticamente, todas as faixas etárias, as prevalências de risco de inadequação de consumo alimentar encontradas indicam que existe, na população estudada, um percentual significativo de indivíduos que não alcançaram os valores de referência. Os achados evidenciam que o padrão alimentar das crianças pernambucanas constitui um problema nutricional de grande porte, o que significa que essas crianças estão em risco de desenvolver deficiência energético-protéica.

Não se pode deixar de chamar a atenção para as limitações implícitas dos inquéritos alimentares. Os resultados deste estudo devem ser considerados com uma certa cautela, em virtude da possibilidade de a metodologia utilizada ter superestimado os percentuais de prevalência de inadequação. A avaliação da ingestão de alimentos por um único recordatório de 24 horas representa a estimativa de ingestão atual e não a habitual, por não considerar a variabilidade intrapessoal|, ${ }^{47}$. Um outro fator a considerar é que a utilização do recordatório de 24 horas tende a subestimar em até $30 \%$ o consumo de energia, em comparação com outros métodos. A subestimação do consumo energético representa o ponto mais conhecido de erro sistemático na avaliação dietética dos indivíduos ${ }^{4}$.

É necessário considerar, no entanto, que qualquer risco de inadequação energética e protéica constitui uma condição desfavorável para o crescimento e desenvolvimento adequados das crianças. Uma das primeiras conseqüências da diminuição da ingestão energética é a estagnação do crescimento. A relação entre o consumo de energia e de proteína é muito estreita. Quando não há um consumo adequado de energia, a utilização de proteínas é prejudicada, sendo esta desviada de sua função na construção de novos tecidos, e utilizada, parcialmente, na produção energética. Dessa maneira, a relação síntese e deposição de proteínas é diretamente influenciada pelo valor energético da alimentação, principalmente, na criança cujo crescimento se apresenta de forma mais acelerada ${ }^{26,27}$.

O Brasil vem apresentando uma significativa tendência de redução da desnutrição infantil nos últimos 25 anos e esse processo tem sido caracterizado pelo desaparecimento de suas formas graves: o kwashiorkor e o marasmo nutricional. No entanto, a desnutrição infantil, em suas formas mais brandas, ainda apresenta percentuais elevados, em comparação aos países desenvolvidos, principalmente, em relação ao índice altura/idade nas populações das regiões Norte, Nordeste e nas áreas rurais ${ }^{1}$.

Neste estudo, o percentual de crianças com déficit nutricional para os índices peso/idade, peso/estatura e estatura/idade (<-2 escores-Z) foi de $7,3 \%, 1,5 \%$ e $16,1 \%$, respectivamente, superando as prevalências esperadas em países desenvolvidos $(2,3 \%)^{14}$.

Em relação ao risco nutricional, ou seja, os indivíduos situados entre -2 e -1 desvio-padrão, os percentuais encontrados foram maiores que 0 
esperado para uma população normal (13,6\%), sendo $16,4 \%$ e $23,5 \%$ para os índices peso/idade e estatura/idade, respectivamente ${ }^{5}$.

As menores prevalências de desnutrição e risco nutricional foram encontradas ao classificar as crianças quanto ao índice peso/estatura. Esses indicadores se referem à hipotrofia ou magreza, representando um processo grave e recente de fome, que tem como conseqüência a perda significativa de peso, expressando uma desarmonia no processo de crescimento ${ }^{14}$.

Na literatura, a relação entre a desnutrição e o consumo alimentar está bem documentada23,24,28. No entanto, são raros os estudos epidemiológicos que abordam esse assunto ${ }^{20}$. O fato de o ENDEF (1974/75) não dispor de informações sobre a distribuição intra-familiar do consumo alimentar inviabiliza a análise da adequação nutricional da alimentação das crianças. Contudo, considerando que a adequação alimentar da família expressa, de alguma forma, a adequação alimentar de seus componentes, Viacava et al. ${ }^{6}$ realizaram uma associação entre a adequação energética e protéica da família e o estado nutricional de crianças de 12-59 meses. Os resultados mostraram que o percentual de crianças eutróficas foi maior nas famílias em cuja alimentação havia adequação energética e protéica.

No presente estudo, verificou-se que o estado nutricional (em média do escore-Z) das crianças com consumo energético e protéico abaixo da referência, foi pior do que o daquelas que alcançaram as recomendações, na maioria das faixas etárias. O padrão alimentar de energia e proteína sugere ser este o fator determinante do desencadeamento dos déficits ponderal, de hipotrofia e estatural, com repercussões, sobretudo, no crescimento estatural.

A privação energética e protéica das crianças no Estado de Pernambuco, repercutindo diretamente no seu estado nutricional, é um relevante problema de saúde pública. Os resultados aqui apresentados reforçam a necessidade de monitoramento da ingestão alimentar de crianças menores de cinco anos, no sentido de evitar a inadequação alimentar e nutricional, um procedimento fundamental para a formulação de políticas públicas de segurança alimentar e nutricional.

\section{COLABORADORES}

R.C.E. MENEZES e M.M. OSÓRIO participaram da concepção da pesquisa, revisão da literatura, processamento, análise dos dados e redação do artigo.

\section{REFERÊ NCIAS}

1. Batista Filho $M$, Rissin $A$. A transição nutricional no Brasil: tendências regionais e temporais. Cad Saúde Pública. 2003; 19(Supl 1):181-91.

2. Sigulem DM, Devincenzi UM, Lessa AC. Diagnóstico do estado nutricional da criança e do adolescente. J Pediatr. 2000; 76 (Supl 3): 275-84.

3. Galeazzi MAM, Domene SMA, Sichieri R. Estudo multicêntrico sobre consumo alimentar. Cad Deb. 1997; Volume Especial: 62p.

4. Ferro-Luzzi A. Individual food intake survey methods. International Scientific Symposium on Measurement and Assessment of Food and Deprivation and Undernutrition. Rome; 2002.

5. Vasconcelos FAG. Avaliação nutricional de coletividades. Florianópolis: Editora da Universidade Federal de Santa Catarina; 2000.

6. Viacava F, Figueiredo CMP, Oliveira WA. A desnutrição no Brasil. Petrópolis: Vozes; 1983.

7. Batista Filho M, Romani SAM. Alimentação, nutrição e saúde no estado de Pernambuco: espacialização e fatores socioeconômicos. Recife: Instituto Materno Infantil de Pernambuco; 2002.

8. Pernambuco. Governo do Estado. Crianças e adolescentes em Pernambuco: saúde, educação e trabalho. Recife: Unicef; 1992.

9. Philippi ST, Szarfarc FC, Latterza AR. Virtual Nutri, versão 1.0 para Windows [software]. São Paulo: Universidade de São Paulo, Faculdade de Saúde Pública, Departamento de Nutrição; 1996.

10. Brasil. Ministério da Saúde. Secretaria de Políticas de Saúde. Coordenação Geral da Política de Alimentação e Nutrição. Alimentos regionais brasileiros. Brasília; 2002. 140p. Série F: Comunicação e Educação em Saúde, n. 21.

11. Instituto Brasileiro de Geografia e Estatística. Tabelas de composição de alimentos. Rio de Janeiro; 1977. 
12. Institute of Medicine. National Research Council. Dietary reference intakes: applications in dietary assessment. Washington (DC): National Academy Press; 2001.

13. Institute of Medicine. National Research Council. Dietary reference intakes for energy, carbohydrate, fiber, fat, fatty acids, cholesterol, protein and amino acids (macronutrients). Washington (DC): National Academy Press; 2002.

14. World Health Organization. Physical status: the use and interpretation of anthropometry. Geneva: 1995.

15. Farias Júnior G, Osório MM. Padrão alimentar de crianças menores de 5 anos. Rev Nutr. 2005; 18(6):793-802.

16. Oliveira MAA. Consumo de leite de vaca e anemia em crianças de 6 a 59 meses de idade no estado de Pernambuco [tese]. Recife: Universidade Federal de Pernambuco; 2005.

17. Slater B, Marchioni DL, Fisberg RM. Estimando a prevalência da ingestão inadequada de nutrientes. Rev Saúde Pública. 2004; 38(4):599-605.

18. Mondini L, Monteiro CA. Mudanças no padrão alimentar da população urbana brasileira (1962-1988). Rev Saúde Pública. 1994; 28(6): 433-9.

19. Assis AMO, Barreto ML. Condições de vida, saúde e nutrição na infância em Salvador. Salvador: Bureau; 2000.

20. Barquera S, Rivera JA, Safdie M, Flores M, Campos-Nonato I, Campirano F. Energy and nutrient intake in preschool and school age Mexican children: National Nutrition Survey 1999. Salud Públ Méx. 2003; 45(Suppl. 4):540-50.

21. Spinelli MGN, Goulart RMM, Santos ALP, Gumiero LC, Farhud CC, Freitas EB, et al. Consumo alimentar de crianças de 6 a 18 meses em creches. Rev Nutr. 2003; 16(4):409-14.

22. Szarfarc SC, Monteiro CA, Meyer M, Tudisco ES, Reis IM. Estudo das condições de saúde das crianças do município de São Paulo, SP (Brasil), 1984/1985 X. Consumo alimentar. Rev Saúde Pública. 1988; 22(4):266-72.

23. Medeiros LCS, Speridião PGL, Sdepanian VL, Fagundes-Neto $U$, Morais MB. Ingestão de nutrientes e estado nutricional de crianças em dieta de leite de vaca e derivados. J Pediatr. 2004; 80(5): 363-70.

24. Castro TG, Novaes JF, Silva MR, Costa NMB, Franceschini SCC, Tinôco ALA, et al. Caracterização do consumo alimentar, ambiente socioeconômico e estado nutricional de pré-escolares de creches municipais. Rev Nutr. 2005; 18(3):321-30.

25. World Health Organization. Complementary feeding of young children in developing countries: a review of current scientific knowledge. Geneva; 1998.

26. Amaral FP. Discriminação e mistificação em alimentação. A FAO, a OMS, etc. contra os povos subdesenvolvidos! São Paulo: Alfa-Omega; 1996.

27. Marchini JS, Fausto MA, Rodrigues MMP, Oliveira JED, Vannucchi H. Necessidades e recomendações de proteínas: revisão, atualização e sugestões. Cad Nutr. 1993; 6(1):1-21.

28. Batista Filho M. Alimentação, nutrição e saúde. In: Rouquayrol MZ. Epidemiologia e saúde. Rio de Janeiro: Medsi; 2003. p. 389-414.

Recebido em: 12/5/2006

Versão final apresentada em: 29/1/2007 Aprovado em: 8/2/2007 